Os 10 anos do atual programa de moradia social no Brasil: uma trajetória de (des)caminhos.

Revista Ensaios, vol. 14, jan-jun de 2019.

\title{
Os 10 anos do atual programa de moradia social no Brasil: uma trajetória de (des)caminhos
}

\author{
Ciro Andrade da Silva ${ }^{1}$ \\ Rafael Soares Gonçalves ${ }^{2}$
}

Resumo: O artigo apresenta um estudo do Programa Minha Casa Minha Vida (PMCMV), o principal programa governamental brasileiro, voltado à produção da moradia social na atualidade. Para o estudo utiliza-se de dados coletados a partir de órgãos oficiais, leis, normas, fontes documentais que se refere ao programa. Percebe-se que, embora tenha respondido ao aumento da oferta de habitação social, permitindo a diminuição do déficit habitacional, não previu a participação popular nas etapas de sua implementação e atendeu sobretudo aos interesses das empresas construtoras. O programa em tela acaba repetindo erros do passado, que provocaram forte periferização da moradia social, principalmente nas grandes cidades.

Palavras-chave: Habitação; Habitação social; Política Social.

\begin{abstract}
The article presents a study of the Minha Casa Minha Vida Program (PMCMV) the main Brazilian government program focused on the production of social housing today. To study, we use data collected from official government departments, laws, standards, sources that refer to the program. Although it has responded to the increase in the supply of social housing, allowing the reduction of the deficit, as it does not have a popular participation in the stages of its implementation and attending almost exclusively to the interest of the construction companies, the program repeating errors of the past which caused a strong peripheralization of popular housing, especially in large cities.
\end{abstract}

Keywords: Housing; Social Housing; Social Policy.

\footnotetext{
${ }^{1}$ Universidade Federal dos Vales do Jequitinhonha e Mucuri (UFVJM), Departamento de Serviço Social, Diamantina, MG, Brasil. vemciro@gmail.com.

${ }^{2}$ Pontifícia Universidade Católica do Rio de Janeiro (PUC-RJ), Programa de Pós-graduação em Serviço Social, Rio de Janeiro, RJ, Brasil. rafaelsgoncalves@yahoo.com.br.
} 
Os 10 anos do atual programa de moradia social no Brasil: uma trajetória de (des)caminhos.

Revista Ensaios, vol. 14, jan-jun de 2019.

O Programa Minha Casa Minha Vida (PMCMV) foi criado pela Lei Federal $n^{\circ}$. 11.977, de 07 de julho de 2009, em um contexto global de grande crise econômicofinanceira, tendo a meta inicial de criação de um milhão de unidades habitacionais em todo o território nacional. Esse grande investimento se deu sem o devido controle social por parte da sociedade civil organizada. Seus recursos principais não resolveram problemas urbanísticos de áreas urbanas consolidadas em situação de vulnerabilidade social, como é o caso da regularização de favelas. Conforme será analisado, apesar do PMCMV ter significado um aumento importante na oferta de habitação social, ele pouco dialogou com a reflexão que vinha sendo empreendida no contexto da criação do Sistema Nacional de Habitação de Interesse Social.

O PMCMV se mostrou desarticulado de um projeto mais democrático de cidade e não priorizou aspectos essenciais de uma política habitacional mais ampla (acesso aos equipamentos sociais: transporte público, creches, escola, postos de saúde). As novas moradias, sobretudo aquelas voltadas para os grupos de mais baixa renda, são geralmente de baixa qualidade, situadas em sua grande maioria em áreas extremamente distantes e ermas, o que implica em custos importantes para os beneficiários do programa. $\mathrm{O}$ PMCMV acabou reproduzindo velhas estratégias de expansão das unidades habitacionais com expansão da própria periferia (e os clássicos problemas de infraestrutura urbana que nela subjazem). Trata-se, assim de um avanço no que respeita ao montante investido para a população mais pobre, mas de forte retrocesso quer seja na qualidade dos empreendimentos, quer seja na articulação da política habitacional com a política de acesso à cidade, conforme será demonstrado ao longo do presente artigo.

\section{Os caminhos e descaminhos da atual política habitacional do Brasil}

As primeiras iniciativas para a promoção de habitação para a classe operária ficaram à cargo das indústrias, com a construção das Vilas Operárias no início do século XX, que foram beneficiadas por isenções fiscais. Novas medidas foram sendo implementadas no decorrer do século XX, conforme descreve brevemente o quadro a seguir. 
Os 10 anos do atual programa de moradia social no Brasil: uma trajetória de (des)caminhos.

Revista Ensaios, vol. 14, jan-jun de 2019.

Quadro 01 - Iniciativas de habitação até final do século XX.

\begin{tabular}{|c|c|}
\hline $\begin{array}{c}\text { Estratégias no campo da } \\
\text { habitação }\end{array}$ & Período \\
\hline Vilas operárias (iniciativa privada) & XX. \\
\hline $\begin{array}{c}\text { Carteiras prediais dos IAPs } \\
\text { (iniciativa pública) }\end{array}$ & $1937-1964$ \\
\hline $\begin{array}{c}\text { Fundação da Casa Própria (iniciativa } \\
\text { pública) }\end{array}$ & $1946-1964$ \\
\hline $\begin{array}{c}\text { Banco Nacional de Habitação (BNH) } \\
\text { (iniciativa pública) }\end{array}$ & $1964-1985$ \\
\hline
\end{tabular}

\section{Fonte: Silva 2015.}

Tanto os Institutos de Aposentadoria e Pensão (IAPs) e, posteriormente, a Fundação da Casa Própria iniciaram a provisão de moradias populares, mas essa questão só ganha volume considerável a partir da implantação do Banco Nacional de Habitação (BNH) durante o Regime Militar (1964-1985). A habitação no período militar procurou estimular sobretudo o acesso à propriedade privada, cabendo ao Estado promover o financiamento de moradia às famílias inseridas no mercado de trabalho e que tivessem condições de arcar com os custos do financiamento. Como avaliou Taschner (1997), dos 4,5 milhões de moradias realizadas no período, somente 723 mil foram realmente destinadas à população de baixa renda.

Tratou-se de uma política pautada na concentração de renda e no incentivo à indústria da construção civil, que gerou empregos para legitimar o regime e ajudou a amenizar os conflitos de classe na época. A política de habitação no Brasil, desde o fim do Banco Nacional de Habitação (BNH), em 1986, não contava com uma política de construção de moradia em grande escala.

O período de abertura política foi caracterizado por forte recessão, inflação, desemprego em massa, o que reforçou o processo de achatamento salarial estimulado pelo regime militar. Foi um período também de fortes mobilizações da sociedade. A forte participação dos movimentos urbanos nas mobilizações retoma o debate da reforma urbana, timidamente esboçada nos anos 1960. O Fórum Nacional Pela Reforma Urbana 
Os 10 anos do atual programa de moradia social no Brasil: uma trajetória de (des)caminhos.

Revista Ensaios, vol. 14, jan-jun de 2019.

$(\text { FNRU })^{3}$ se organiza no contexto da Assembleia Constituinte e parte de sua pauta é incluída no capítulo constitucional sobre a reforma urbana (artigos 182 e 183). Além de dispor sobre a função social da cidade e da propriedade, o capítulo concede forte centralidade ao município na construção das políticas urbanas, sobretudo na produção do plano diretor. Assegura, ainda, a participação popular no processo de gestão das cidades.

Com a aprovação da Constituição Federal de 1988, travou-se uma nova luta para a regulamentação do capítulo de política urbana, que se concretizou parcialmente com a promulgação do Estatuto da Cidade (Lei 10.257 de 2001). Dessa forma, a implementação da atual política de habitação social pode ser brevemente resumida no quadro a seguir:

Quadro 02 - Os caminhos da nova política de habitação no Brasil

\begin{tabular}{|c|c|}
\hline Data/ano & Episódio ou evento \\
\hline 1991 & $\begin{array}{c}\text { Apresentado o projeto de lei de iniciativa popular que } \\
\text { propõe a instituição do Fundo Nacional de Moradia }\end{array}$ \\
\hline 2001 & Aprovado o Estatuto das Cidades \\
\hline 2003 & Criado o Ministério das Cidades \\
\hline 2003 & Realizada a 1 ${ }^{\text {a Conferência Nacional das Cidades. }}$ \\
\hline 2004 & $\begin{array}{c}\text { Instalado o Conselho Nacional da Cidade } \\
\text { Mais de 2000 municípios haviam elaborado seus planos } \\
\text { diretores. }\end{array}$ \\
\hline $2003 / 2006$ & $\begin{array}{c}\text { Aprovada a criação do Sistema Nacional de Habitação de } \\
\text { Interesse Social }\end{array}$ \\
\hline 2006 & $\begin{array}{c}\text { Implementação do Fundo Nacional de Habitação de } \\
\text { Interesse Social }\end{array}$ \\
\hline 2009 & Criação do Programa Minha Casa Minha Vida \\
\hline
\end{tabular}

Fonte: Silva (2015).

${ }^{3}$ O FNRU - foi protagonista em diversos projetos de iniciativa popular. Sua coordenação é composta por vários movimentos sociais urbanos, institutos de pesquisa, associação de trabalhadores, conselhos classistas e fóruns regionais. 
Os 10 anos do atual programa de moradia social no Brasil: uma trajetória de (des)caminhos.

Revista Ensaios, vol. 14, jan-jun de 2019.

A atual política de habitação é fruto de um processo de amadurecimento de propostas desenvolvidas por vários segmentos da sociedade, envolvidos na luta pela reforma urbana, ao longo do período pós-BHN. A política de subsídios previa um "mix" de recursos não onerosos com recursos retornáveis do Fundo de Garantia por Tempo de Serviço (FGTS) para viabilizar o crédito e o acesso à moradia digna para a população de baixa renda, basta lembrar que esse modelo já estava sendo aplicado no governo do Presidente Fernando Henrique Cardoso (FHC) via o Plano de Arrendamento Residencial. A estratégia seria concentrar o FGTS na baixa renda e a retomada do mercado para atender a classe média. Da mesma forma, consolidou-se a ideia que a questão da habitação não podia ser enfrentada sem forte intervenção pública no mercado imobiliário e de modo articulado com a questão urbana, ficando claro, conforme sustenta Bonduki (2014), que o problema da moradia não se resolvia apenas com construção de casinhas.

O Ministério das Cidades (MCidades), criado em 2003, no primeiro dia de governo do Presidente Luiz Inácio Lula da Silva, procurou, com quatro secretarias nacionais Habitação, Saneamento, Mobilidade Urbana e Programas Urbanos -, articular as políticas setoriais e enfrentar a questão urbana. Estava sob a coordenação inicial do Ministro Olívio Dutra (PT-RS), e era composto por uma equipe comprometida com a agenda da reforma urbana e com a luta pelo direito à moradia. ${ }^{4}$

Em outubro de 2003, foi realizada a Primeira Conferência Nacional das Cidades, com 2,5 mil delegados eleitos num amplo processo de mobilização social, em mais de três mil municípios, consolidando as bases da atuação do governo, que propôs a criação e a composição do Conselho das Cidades, instalado em 2004. Como lembra Matoso e Muniz (2006), uma das principais tarefas do Ministério das Cidades foi estimular a implementação do Estatuto da Cidade, entendido como fundamental para garantir o acesso à terra e viabilizar a produção de habitação social. Para tanto, foi estruturada a

\footnotetext{
${ }^{4}$ A composição inicial, em maio de 2003, contou com o seguinte quadro: Ermínia Maricato (Professora da FAU - USP, Arquiteta e urbanista do campo da reforma urbana, ex-Secretária de habitação do governo Erundina na cidade de São Paulo) para a Secretária Executiva do Ministério; José Carlos Xavier (vasta experiência na área de transportes na gestão petista na cidade de Goiânia) para Secretaria Nacional de Transportes; Raquel Rolnik (Arquiteta e Urbanista, membro do Fórum Nacional de Reforma Urbana) para a Secretaria de Programas Urbanos. José Fontes Hereda (Arquiteto e Urbanista ex-Secretário de Habitação de Diadema - SP), para a Secretaria de Habitação; Abelardo de Oliveira Filho (sindicalista baiano, expresidente da Empresa Baiana de Águas e Saneamento (EMBASA), para a Secretaria Nacional de Saneamento (SERAFIM, 2012, p.07) e Edésio Fernandes (jurista e uma das maiores autoridades em regularização fundiária do país) como Diretor nacional dos assuntos fundiários do ministério.
} 
Os 10 anos do atual programa de moradia social no Brasil: uma trajetória de (des)caminhos.

Revista Ensaios, vol. 14, jan-jun de 2019.

Campanha Nacional pelo Plano Diretor Participativo, desenvolvida pela Secretaria de Programas Urbanos em 2005, que procurou qualificar técnicos e lideranças comunitárias para, entre outros aspectos, introduzir instrumentos urbanísticos capazes de combater a especulação imobiliária e garantir terra urbanizada para a produção habitacional.

Ainda que, cerca de dois mil municípios brasileiros tenham elaborado seus planos diretores até o ano de 2006, os resultados foram diferenciados e a maioria deles não geraram impactos concretos no sentido de facilitar o acesso à terra para habitação e garantir a função social da propriedade. Muitos dos novos instrumentos previstos nunca foram implementados. Conforme analisa Maricato (2005), após forte pressão do movimento de moradia, as condições começaram a se alterar com a aprovação, em 2005, do Fundo Nacional de Habitação de Interesse Social (FNHIS). A lei no 11.124/05, que criou o FNHIS, instituiu também o Sistema Nacional de Habitação de Interesse Social (SNHIS), que estabeleceu as regras para articular os três entes da federação na implementação da nova Política Nacional de Habitação (PNH). De acordo com essa regulamentação, para terem acesso aos recursos do FNHIS, os estados e municípios precisariam criar uma estrutura institucional específica, incluindo fundo, conselho e planos municipais ou estaduais de habitação. Objetivou-se, assim, estruturar um novo desenho institucional mais descentralizado: “com a pressão e mobilização dos segmentos sociais representados no Conselho das Cidades, elementos-chave da nova política habitacional foram sendo implementados" (BONDUKI, 2014, p. 109).

Com o tempo, percebeu-se alguns avanços, como a destinação de recursos para a compra de imóveis ociosos em áreas centrais para fins habitacionais e a criação de um programa baseado na autogestão, com recursos do Fundo de Desenvolvimento Social (Crédito Solidário). Também é necessário observar que as regras estabelecidas nos programas do FGTS inviabilizaram soluções habitacionais nas regiões metropolitanas, por causa do alto preço e da escassez de terras aptas para a produção de moradias novas. Em 2004, foi aprovada pelo Congresso Nacional, com forte apoio do governo e do setor empresarial, a Lei $n^{\circ} 10.931$, que deu segurança jurídica ao mercado ao criar a alienação fiduciária e obrigar o pagamento do incontroverso valor de crédito sobre o qual não há discordância entre credor e devedor no caso de conflito jurídico entre o mutuário e o agente financeiro. Já em 2005, o Banco Central passou a exigir que 65\% do saldo do 
Os 10 anos do atual programa de moradia social no Brasil: uma trajetória de (des)caminhos.

Revista Ensaios, vol. 14, jan-jun de 2019.

Sistema Brasileiro de Poupança e Empréstimo (SBPE) fossem utilizados para aplicação da produção habitacional. Em um quadro favorável de crescimento da economia, do nível de emprego e dos salários, essas medidas geraram uma aceleração na produção e comercialização de unidades habitacionais para o setor médio. A aplicação em habitação no SBPE saltou de 2,2 bilhões de reais em 2002 para cerca de 80 bilhões de reais, em $2011^{5}$.

A conjuntura contemporânea gerou forte interesse dos investidores no mercado habitacional brasileiro, que, por mais de 20 anos, tinha ficado aquém da sua potencialidade. Ocorreu, nos anos seguintes, uma avassaladora procura por terrenos e glebas aptos para habitação, em um processo especulativo que chegou a ser considerado, entre 2007 e 2008, um princípio de boom imobiliário. Como consideraram Silva (2015) e Bonduki (2014), essa demanda criou uma disputa por terra, com efeitos nefastos para a produção de habitação de interesse social.

As condições macroeconômicas do Brasil vinham melhorando sensivelmente a partir de 2005, apontando para a viabilização do modelo financeiro proposto para aplicação na política de habitação. Este quadro confirmou-se nos anos seguintes com a implementação do Fundo Nacional de Habitação de Interesse Social (FNHIS) (2006), do Programa de Aceleração do Crescimento-PAC (2007) e do Programa Minha Casa Minha Vida(2009), que elevaram substancialmente os recursos destinados à habitação.

Conforme lembrou Serafim (2012), em julho de 2006, em meio a mais grave crise do seu governo, conhecida como "Mensalão", o presidente Lula foi obrigado a trocar Olívio Dutra por um ministro indicado pelo conservador Partido Progressista (PP), agremiação do então presente da Câmara Federal, Severino Cavalcanti, eleito sem o apoio do governo, para garantir a governabilidade e reforçar a sua posição no Congresso Nacional. Essa mudança culminou no desmonte do ministério, até então formado por uma equipe comprometida com a formulação de uma política urbana articulada para o país. Em 2007, o governo lançou o Programa de Aceleração do Crescimento (PAC),

\footnotetext{
$5 \quad$ Mesmo voltado para segmentos médios, o aumento da oferta de unidades habitacionais contribui para o enfrentamento do déficit habitacional, pois o mercado formal e o informal de moradias funcionam como vasos comunicantes. A falta de oferta do segmento médio tende a elevar o custo das moradias populares, mesmo que informais e a sugar as unidades de habitação social, produzidas com subsídio, para quem dele não tem necessidade como aconteceu em toda história da produção pública.
} 
Os 10 anos do atual programa de moradia social no Brasil: uma trajetória de (des)caminhos.

Revista Ensaios, vol. 14, jan-jun de 2019.

objetivando implantar grandes obras de infraestrutura, que incluiu, entre seus componentes, um programa de caráter social, o Programa de Urbanização de Assentamentos Precários, prevendo recursos orçamentários inusitados para o setor de habitação. Entre 2003 e 2008, os recursos totais destinados à habitação elevaram-se de cerca de $\mathrm{R} \$ 8$ bilhões para mais de $\mathrm{R} \$ 42$ bilhões. O elevado montante de recursos tornou mais evidente a necessidade de uma maior articulação com a política urbana e fundiária, mas que deixou de ser definitivamente uma prioridade do Ministério das Cidades. O último esforço para enfrentar essa questão foi realizado pela Secretaria Nacional de Habitação, na elaboração do Plano Nacional de Habitação (PlanHab) ${ }^{6}$, realizado entre 2007 e 2008.

Conforme descreveram Cardoso (2009) e Bonduki (2014), por meio do Plano Nacional de Habitação (PlanHab), foram quantificadas, pela primeira vez, de modo consistente, as necessidades habitacionais do Brasil, considerando a dinâmica demográfica. Chegou-se, assim, a conclusão de que até 2023 seria necessário produzir cerca de 34,9 milhões de unidades habitacionais, sendo 7,9 milhões para eliminar o déficit existente e 27 milhões para atender as necessidades futuras. Isso sem contar com a necessidade da urbanização de assentamentos precários, onde vivem 3,3 milhões de famílias e da complementação de infraestrutura em assentamentos que reúnem 9,8 milhões de pessoas.

No segundo semestre de 2008, quando o Plano Nacional de Habitação (PlanHab) estava sendo concluído, a crise econômica global, fortemente associada ao crédito habitacional nos Estados Unidos, chegou ao Brasil, gerando incertezas e paralisia no setor imobiliário, que estava em pleno processo de aceleração da produção. A conjuntura foi determinante na decisão governamental inédita de priorizar o investimento público no setor habitacional, com o objetivo de evitar o aprofundamento da crise de mercado. Em

\footnotetext{
$6 \quad$ Foi desenvolvido por meio de uma metodologia participativa e com consultoria do Laboratório de Habitação e Assentamentos Humanos da FAU-USP e do Instituto Via Pública. OPlano Nacional de Habitação (PlanHab) foi concebido como um plano estratégico de longo prazo articulado com propostas operacionais a serem implementadas a curto e médio prazo, tendo como horizonte o ano de 2023. Sua elaboração contou com amplo processo participativo, e envolveu todos os segmentos da sociedade durante 18 meses. Suas propostas, estratégias de ação e metas, amplamente debatidas, procuraram considerar a diversidade da questão habitacional, as variadas categorias de municípios, as especificidades regionais e os diferentes olhares de cada segmento social (BONDUKI, 2009, p.03).
} 
Os 10 anos do atual programa de moradia social no Brasil: uma trajetória de (des)caminhos.

Revista Ensaios, vol. 14, jan-jun de 2019.

consequência, começou a ser formulado um novo programa habitacional, que veio a ser chamado de Minha Casa Minha Vida, que será melhor descrito a seguir.

\section{Repercussões sobre o Programa Minha Casa Minha Vida}

No segundo semestre de 2008, a crise econômica internacional, que teve início no setor imobiliário americano, chegou ao Brasil, gerando incertezas e uma paralisia no setor, pois estava-se em pleno processo de aceleração da produção. A situação pareceu fugir de controle, com acentuada queda no valor das ações das empresas do setor imobiliário na bolsa de valores e com evidentes impactos nas atividades do setor, que sofreu forte queda nos últimos meses daquele ano. Como parte do pacote de medidas destinado a combater os efeitos da crise, o Governo Lula lançou, em março de 2009, o Programa Minha Casa Minha Vida (PMCMV), com a proposta de construir um milhão de moradias no período de 2 anos. Conforme afirma Silva (2015), foi a partir da pressão por parte dos movimentos sociais, no mesmo ano, que foi também foi lançado o Programa Minha Casa Minha Vida na modalidade entidades (PMCMV- Entidades), voltado a destinar recursos à moradia de famílias organizadas por meio de cooperativas habitacionais, associações e demais entidades privadas sem fins lucrativos.

A modalidade Entidades do PMCMV, criada em 2009, teve por objetivo estabelecer as condições para a análise e aprovação das propostas ou projetos de intervenção recebidas das Entidades Organizadoras, bem como a concessão de financiamento habitacional às famílias de baixa renda, organizadas sob a forma coletiva, para viabilizar o acesso à moradia em área urbana, com recursos do Fundo de Desenvolvimento Social (FDS). Nessa modalidade, a Entidade Organizadora pode solicitar junto à Secretaria Nacional de Habitação/M. Cidades sua habilitação. Com relação aos critérios de exigibilidade, essenciais para o processo de habilitação, estão a seguir colocados: a) atividade da entidade por no mínimo 3 anos; b) compatibilidade social entre os seus objetivos e do Programa; c) experiência na gestão de obras habitacionais (entendido com gestão e mobilização da demanda, a elaboração de projetos habitacionais, administração de recursos para moradia ou acompanhamento pós-ocupação de empreendimentos); d) transparência na gestão da entidade. Na modalidade em causa, a Caixa Econômica 
Os 10 anos do atual programa de moradia social no Brasil: uma trajetória de (des)caminhos.

Revista Ensaios, vol. 14, jan-jun de 2019.

Federal é responsável pela orientação da entidade e beneficiários sobre a formulação de propostas, também se responsabiliza em analisar a proposta sob os aspectos: a) jurídico/cadastral; b) de engenharia e de trabalho social; c) formalizar e contratar as operações de financiamento com os beneficiários e liberar os recursos. Já a entidade organizadora (representada por cooperativas, associações e entidades da sociedade civil sem fins lucrativos) tem as atribuições de arregimentar, congregar, organizar e apoiar as famílias no desenvolvimento de cada uma das etapas dos projetos voltados para a solução dos seus problemas habitacionais, sendo ainda responsável perante a CEF pela execução da intervenção, juntamente com os beneficiários e a Comissão de Acompanhamento de Obra (SILVA 2015, p.171).

Por sua vez, a execução do PMCMV se dá em duas vertentes principais: no caso de unidades habitacionais para famílias com renda de até três salários mínimos, a Caixa Econômica Federal (CEF) paga a empreiteiras que apresentem propostas para a construção de moradias em áreas nas quais há déficit habitacional e, depois de concluída a obra, os imóveis são repassados às famílias cadastradas pela Caixa. No caso de unidades para famílias com renda entre três e dez salários mínimos, o programa garante financiamento às construtoras, que posteriormente vendem as unidades habitacionais, segundo valores definidos com base na renda das famílias.

A partir dos dados oficiais fornecidos pela CEF (2009), as principais características do Programa são, resumidamente, as seguintes:

a) Habitações para famílias com rendas de até três salários mínimos ou faixa 01:

O objetivo é a aquisição de empreendimentos na planta, para famílias com renda bruta de até 3 salários mínimos. No que se refere à abrangência, o programa procurou atender capitais e respectivas regiões metropolitanas, bem como municípios com mais de 100 mil habitantes, podendo contemplar, em condições especiais, municípios entre 50 e 100 mil habitantes, de acordo com seu déficit habitacional. No quesito funcionamento, a união aloca recursos por área do território nacional e solicita a apresentação de projetos. Os Estados e municípios realizam cadastramento da demanda e, após triagem, indicam famílias para seleção, utilizando as informações do Cadastro Único. As construtoras apresentam projetos às superintendências regionais da $\mathrm{CEF}$, podendo fazê-los em parceria 
Os 10 anos do atual programa de moradia social no Brasil: uma trajetória de (des)caminhos.

Revista Ensaios, vol. 14, jan-jun de 2019.

com o Estado, municípios, cooperativas, movimentos sociais ou independentes. Após análise simplificada, a CEF contrata a operação, acompanha a execução da obra pela construtora, libera recursos conforme cronograma e, concluído o empreendimento, realiza a sua comercialização.

As condições de acesso ao programa são as seguintes: i)não ter sido beneficiado anteriormente em programas de habitação social do governo; ii)não possuir casa própria ou financiamento em qualquer unidade da federação; iii)estar enquadrado na faixa de renda familiar do programa; iv)pagamento de $10 \%$ da renda durante 10 anos, com prestação mínima de $\mathrm{R} \$ 50,00$, corrigida pela taxa referencial (TR), v)registro do imóvel preferencialmente em nome da mulher, sem entrada e sem pagamento durante a obra, assim como não há cobrança de seguro por Morte e Invalidez Permanente (MIP) e Danos Físicos do Imóvel (DFI).

Em relação à operacionalização, o beneficiário dirige-se à prefeitura, estado da federação ou movimento social (no caso específico do projeto Minha Casa Minha Vida Entidades) para cadastrar-se. Após a seleção, é convocado para apresentação da documentação pessoal (na $\mathrm{CEF}$, correspondente imobiliário, prefeitura ou outros credenciados). A assinatura do contrato ocorre na entrega do empreendimento.

b) Habitação para famílias com renda acima de 3 e até 10 salários mínimos, faixas 02 e 03:

As famílias com renda acima de 3 e até 6 salários mínimos (faixa 2) beneficiaramse de um aumento substancial do valor do subsídio nos financiamentos com recursos do FGTS. Aquelas com renda acima de 6 e até 10 salários mínimos (faixa 3) contarão com redução dos custos de seguro e acesso ao Fundo Garantidor da Habitação. Com relação às condições para contratação de pagamento, o financiamento alcança até $100 \%$ do custo de construção.

No que diz respeito aos juros nominais, estão assim especificados: i) Renda de 3 a 5 salários mínimos (faixa 02) - 5\% ao ano + Taxa Referencial (TR); ii) Renda de 5 a 6 salários mínimos (faixa 03) - 6\% ao ano + Taxa Referencial (TR); iii) Renda de 6 a 10 salários mínimos (Faixa 04) - 8,16\% ao ano + Taxa Referencial ( TR). 
Os 10 anos do atual programa de moradia social no Brasil: uma trajetória de (des)caminhos.

Revista Ensaios, vol. 14, jan-jun de 2019.

Em todas as modalidades, é necessária a comprovação de renda com apresentação da declaração do Imposto de Renda de Pessoa Física e há análise cadastral junto aos seguintes órgãos: Centralização de Serviços aos Bancos (SERASA), Banco Central do Brasil (BACEN), Serviço de Proteção ao Crédito (SPC), Cadastro Informativo de Créditos não quitados no setor público Federal (CADIN), inscrição junto ao Cadastro Nacional de Mutuário (CDMUT). Também é realizada uma análise de risco com a capacidade de pagamento como é de praxe nos financiamentos imobiliários.

A crise econômica e a disposição do governo em aplicar fartos recursos para dinamizar a construção civil através do PMCMV, atropelaram o processo de construção do PlanHab, pactuado como uma estratégia de longo prazo para equacionar o problema habitacional.

Conforme analisa Cardoso (2011), o PMCMV, em sua componente urbana, foi operacionalizado a partir da alocação de recursos da União ao Fundo de Arrendamento Residencial (FAR) - no montante de 14 bilhões de reais - e, em menor grau, ao Fundo de Desenvolvimento Social (FDS) - no montante de 500 milhões de reais -, ambos gerenciados pela Caixa Econômica Federal (CEF).

O FAR já vinha sendo utilizado na produção de unidades habitacionais para famílias com renda entre 3 e 6 salários mínimos, dentro do Programa de Arredamento Residencial (PAR), recebendo recursos transferidos do Orçamento Geral da União (OGU) e do FGTS. Já o FDS havia se constituído como fonte de recursos para o Programa Crédito Solidário (PCS), com objetivo de produção de unidades em regime de autogestão, através de cooperativas ou associações. A partir de então, o PCS passa a ser substituído pelo PMCMVEntidades (CARDOSO, 2011, p. 05).

Ainda segundo Cardoso (2011),

\begin{abstract}
Um dos impactos mais imediatos sobre os programas desenvolvidos no âmbito do FNHIS diz respeito à eliminação dos repasses de recursos para as ações de provisão habitacional. Desde o lançamento do PMCMV, o FNHIS passou a concentrar os seus recursos nas ações de urbanização de assentamentos precários e de desenvolvimento institucional, por orientação do MCid acatada pelo Conselho Gestor. Vale ressaltar que, para 2010, priorizou-se a alocação de recursos em obras complementares a projetos em andamento financiados com recursos do PAC, o que mostra o caráter subsidiário do FNHIS nas decisões de política habitacional, na atual conjuntura (CARDOSO, 2011, p. $05)$.
\end{abstract}

Em ocasião do lançamento do PMCMV, Cardoso (2009) avaliou que seria um programa mais econômico do que habitacional, pois se tratava de uma estratégia voltada 
Os 10 anos do atual programa de moradia social no Brasil: uma trajetória de (des)caminhos.

Revista Ensaios, vol. 14, jan-jun de 2019.

para enfrentar a crise econômica e criar um estímulo à economia. O governo estaria pondo recursos para dinamizar a economia, atuando num setor que tem forte capilaridade econômica e efeito multiplicado, já que a construção atinge setores diversos, tais como vidro, ferro, cimento, madeira, entre outros. O urbanista assinala, ainda, que é um setor com boa absorção de mão-de-obra, configurando-se em um setor chave para estancar os efeitos da crise econômica.

Nas palavras de Cardoso (2009) e Silva (2015), o grande problema do pacote referente ao PMCMV é que ele propôs uma forma de distribuição de recursos federais à margem do Sistema Nacional de Habitação de Interesse Social (SNHIS), que vinha sendo construído desde a criação do Ministério das Cidades. Sendo assim, disponibilizou muitos recursos no sistema, mas fora do controle social democrático sobre sua utilização.

Outra questão que merece destaque é o seu impacto urbanístico. Os novos empreendimentos são localizados em áreas distantes, com ausência de empregos, transporte e equipamentos públicos. Privilegia-se, sobretudo, às empresas de construção. Há, ainda, o risco de impactar o preço da terra, servindo para fins especulativos, o que contrariaria substancialmente os objetivos iniciais do projeto, significando uma transferência do subsídio para fins especulativos. O PMCMV tende a promover uma periferização das intervenções habitacionais nas cidades, uma vez que o aumento do valor do solo provocado pelos empreendimentos força a instalação dos novos empreendimentos em áreas cada vez mais distantes.

Com relação ao alcance do programa, os dados fornecidos, em março de 2019, pela Secretaria Nacional de Habitação do atual Ministério do Desenvolvimento Regional (quadro 03), mostraram os seguintes números:

\section{Quadro 03 - Programa Minha Casa Minha Vida - 10 anos}

\begin{tabular}{|c|l|}
\hline Unidades habitacionais contratadas & 5.582 .626 \\
\hline Unidades Habitacionais concluídas & 4.675 .436 \\
\hline Unidades habitacionais entregues & 4.096 .725 \\
\hline $\begin{array}{c}\text { Investimento pelo orçamento geral } \\
\text { da União (em bilhões) }\end{array}$ & $465.680 .444 .504,41$ \\
\hline
\end{tabular}

Fonte: Ministério do Desenvolvimento Regional - Secretaria Nacional de Habitação (2019) 
Os 10 anos do atual programa de moradia social no Brasil: uma trajetória de (des)caminhos.

Revista Ensaios, vol. 14, jan-jun de 2019.

Os dados foram obtidos através do Sistema Eletrônico do Serviço de Informações ao Cidadão (e-SIC) ${ }^{7}$, com posição até 31 de janeiro de 2019. Passados 10 anos do início do PMCMV, foram contratadas 5.582.626 moradias, sendo que um montante de 4.087.628 já foi entregue. O valor total gasto com as unidades contratadas somou um pouco mais de 465 bilhões de reais.

Com relação aos dados do programa em causa na modalidade entidades, os dados recentes mostram que até o final de 2018 foram contratadas 79.254 unidades habitacionais, as casas entregues somam 17.872, no que respeita às unidades concluídas trata-se de 33.456, já em relação ao valor total empregado, já se somam 2.299.824.091,57 em bilhões como mostra o quadro a seguir:

Quadro 04 - Programa Minha Casa Minha Vida modalidade: Entidades - 10 anos

\begin{tabular}{|c|c|c|c|c|}
\hline ANO & $\begin{array}{c}\mathrm{UH} \\
\text { Contratadas }\end{array}$ & $\begin{array}{r}\mathrm{UH} \\
\text { Entregues }\end{array}$ & $\begin{array}{c}\text { UH } \\
\text { Concluídas }\end{array}$ & Valor Total \\
\hline 2009 & 309 & 213 & 213 & $2.937 .580,56$ \\
\hline 2010 & 7.715 & 3.341 & 4.968 & $73.890 .622,74$ \\
\hline 2011 & 2.988 & 1.407 & 2.501 & $92.350 .527,75$ \\
\hline 2012 & 7.751 & 2.211 & 3.841 & $182.608 .288,87$ \\
\hline 2013 & 16.382 & 2.646 & 7.190 & $324.302 .240,33$ \\
\hline 2014 & 18.737 & 2.544 & 6.245 & $484.559 .010,89$ \\
\hline 2015 & 6.638 & 1.137 & 2.445 & $243.372 .996,77$ \\
\hline 2016 & 11.776 & 1.576 & 3.256 & $346.780 .776,73$ \\
\hline 2018 & 6.790 & 2.797 & 2.797 & $535.849 .904,33$ \\
\hline 2019 & 168 & - & - & $13.172 .142,60$ \\
\hline $\begin{array}{l}\text { Total } \\
\text { Geral }\end{array}$ & 79.254 & 17.872 & 33.456 & 2.299.824.091,57 \\
\hline
\end{tabular}

$7 \quad$ Esse sistema permite que qualquer cidadão solicite dados da administração pública. Os dados foram enviados pelo sistema do portal de acesso à informação do Governo Federal, mediante protocolo do pedido e informação e preenchimento de cadastro. 
Os 10 anos do atual programa de moradia social no Brasil: uma trajetória de (des)caminhos.

Revista Ensaios, vol. 14, jan-jun de 2019.

Fonte: Ministério do Desenvolvimento Regional - Secretaria Nacional de Habitação (2019)

Retomando o debate do programa em sua modalidade convencional, a manifestação de um processo de periferização traz consequências sérias para a população de baixa renda, uma vez que esse grupo se sujeita a ocupar os distantes conjuntos habitacionais, arcando com os elevados custos de transporte no trajeto casa-trabalho-casa, bem como os diversos custos sociais que essa dura rotina de deslocamento provoca.

Para alguns municípios de menor porte, houve ainda a ampliação da demanda por diversos serviços como transporte público, escolas, postos de saúde etc. Os municípios do interior, situados em regiões mais isoladas, não contam com empresas que atendam aos requisitos básicos do programa e que estejam em situação regular com a Caixa Econômica Federal. Portanto, estes municípios não vão contar com o atendimento habitacional e que hoje basicamente se faz por esse programa.

Para além das questões levantadas, há uma padronização dos modelos de casas construídas, não levando em conta, por exemplo, o tamanho das famílias e as diferenças regionais, nomeadamente no que respeita a dinâmica econômica. Dessa forma, as construtoras definem uma planta genérica que se enquadre nas normativas da CEF, garantindo a aprovação de inúmeros projetos similares em diferentes terrenos e geografias.

Bonduki (2013) sintetizou algumas questões relevantes quanto ao PMCMV, designadamente:

1- O Programa MCMV, desarticulado de um projeto de direito à cidade, não priorizou aspectos essenciais de uma política habitacional consistente, como a formulação de uma estratégia fundiária. Assim, ao elevar significativamente a demanda por terras aptas para a produção habitacional para o mercado, o programa gerou valorização do preço dos terrenos e glebas e especulação imobiliária, o que prejudicou, sobretudo, os empreendimentos na faixa social, cujos tetos eram insuficientes para pagar os valores somados pelos abusivos valores fundiários gerados pelo processo especulativo deflagrado. 
Os 10 anos do atual programa de moradia social no Brasil: uma trajetória de (des)caminhos.

Revista Ensaios, vol. 14, jan-jun de 2019.

2- A localização adequada dos projetos depende muito dos municípios, de seus planos diretores e habitacionais e dos instrumentos urbanísticos que eles regulamentam, mas cabe também ao governo federal estimular a implantação dos novos empreendimentos em locais mais adequados e que gerem menor custo urbano, social e ambiental.

3- Embora existam exceções, projetos habitacionais de qualidade e inseridos na malha urbana, a maioria dos empreendimentos do PMCMV está localizada na periferia das cidades, distante do mercado de trabalho, desarticulada da malha urbana existente ou de planos de expansão urbana, com projetos de moradias sem qualidade arquitetônica nem identidade com as comunidades locais pré-existentes. Embora bem-sucedido no quesito de retomada da produção habitacional, o programa não enfrenta a questão urbana e fundiária.

A partir de agosto 2016, período do governo do presidente Michel Temer (31/08/2016 até 31/12/2018), o programa começou a sofrer uma série de cortes, reduzindo a quantidade de contratação de unidades habitacionais em todo o país. Quando tomou posse, em janeiro de 2019, o atual presidente, Jair Bolsonaro, anunciou a extinção do Ministério das Cidades, ficando a secretaria nacional de habitação a pertencer ao Ministério do Desenvolvimento Regional. Não há perspectiva de que o programa terá novos investimentos, já que o governo bloqueou boa parte dos recursos, e anunciou que o Minha Casa Minha Vida passará por uma reavaliação.

\section{Considerações finais}

O PMCMV disponibilizou indubitavelmente um montante significante de recursos para a construção de habitação popular. No entanto, tais recursos, como analisamos, não passam pelo controle da sociedade. O programa se enquadra muito mais em um esforço contra a dura crise econômica deflagrada em 2008, expressando vultosos lucros para a promoção imobiliária e as empresas de construção civil. Além disso, provocou forte periferização da habitação popular nos grandes centros urbanos. Em algumas cidades, como o Rio de Janeiro, o PMCMV foi fundamental para abrigar moradores de favelas, removidos no contexto da preparação da cidade para os grandes eventos que a cidade 
Os 10 anos do atual programa de moradia social no Brasil: uma trajetória de (des)caminhos.

Revista Ensaios, vol. 14, jan-jun de 2019.

recebeu nos últimos anos (Gonçalves, Freire e Bautès, 2017 e Valle e Gonçalves, 2018). Em muitos casos, essas remoções aconteceram de forma autoritária, violando direitos e expulsando a população envolvida para áreas distantes da cidade.

A crítica ao programa foi muito enfatizada, sobretudo pela produção acadêmica referente à sua aplicação no Rio de Janeiro (Cardoso, 2013 e Gonçalves, 2017). No entanto, Ribeiro (2016) sublinhou a exceção da construção de ao menos dois condomínios do programa em áreas mais centrais do Rio de Janeiro, o que atenuou os impactos da periferização excessiva da habitação social. Denaldi (Denaldi, 2012 e Jesus e Denaldi, 2018) reforça também realizações exitosas do programa em outras cidades do país, onde a regulação local logrou atenuar impactos negativos do programa.

O Programa MCMV tem três dimensões muito claras: a) possui uma dimensão econômica forte, já que foi utilizado para criar empregos menos qualificados e beneficiar os setores imobiliários e da construção civil; b) uma dimensão social, já que, apesar dos questionamentos sobre os locais onde foram construídas as moradias, o projeto permitiu a diminuição do déficit habitacional; c) uma dimensão política, já que, no campo do discurso, o programa exerce forte impacto na população mais empobrecida, sendo o primeiro projeto de grande porte na construção de moradia popular desde o BNH e, por fim, d) uma dimensão urbanística, já que impactou sobretudo de forma negativa às cidades, provocando especulação fundiária, periferização da pobreza e a configuração de novas áreas urbanas sem infraestrutura, o que traz impactos sociais aos moradores e a demanda por novos equipamentos.

Da mesma forma, o modelo de organização da gestão dos prédios é problemático. O PMCMV estimulou a formação de condomínios, o que acarreta custos importantes aos moradores e desobriga os poderes públicos dos custos de manutenção dos espaços comuns. A falta de pagamento das taxas condominiais implica em problemas no fornecimento de serviços públicos, sobretudo água. O fato de a tipologia de construção dos edifícios reproduzir condomínios fechados, aliado à realidade que muitos empreendimentos foram erguidos em áreas distantes, implica, ao menos no caso da região metropolitana da cidade do Rio de Janeiro, o paulatino controle espacial dessas áreas pelo tráfico ou, sobretudo, pela milícia. A pretensa solução formulada pelo programa pode estar se convertendo também em um grande problema de amanhã. 
Os 10 anos do atual programa de moradia social no Brasil: uma trajetória de (des)caminhos.

Revista Ensaios, vol. 14, jan-jun de 2019.

\section{Referências:}

BONDUKI, Nabil. Habitação, Estado e Movimento moderno: A ação dos IAPS. Anais do VI Encontro Nacional da ANPUR. Brasília, Associação Nacional de Pós-Graduação e Pesquisa em Planejamento Urbano e Regional, p. 836-851,1995. 732,1994 .

Origens da habitação no Brasil, Análise Social, v. XXIX, n. 127, p.711-

Origens da Habitação social no Brasil: arquitetura moderna, lei do inquilinato e difusão da casa própria. $6^{\text {a }}$ ed., São Paulo: Estação liberdade, 2011.

Os Pioneiros da habitação social no Brasil; volume 01. São Paulo: Editora Unesp: Edições Sesc, 2014.

Do projeto Moradia ao Programa Minha Casa Minha Vida, Revista teoria e debate, v.82, 2009, p.01-10.

CARDOSO, Adauto Lúcio, Notas metodológicas sobre o déficit habitacional. Rio de Janeiro, IPPUR, UFRJ, 2001.

Balanço da política municipal de habitação 2001-2003. São Paulo: Instituto Polis; PUC-SP, 2004. 104p

Política Habitacional no Brasil: balanços e perspectivas. ANPUR/ UFRJ. Rio de Janeiro,2003, p.01-11. Disponível em: $<$ http://www.observatoriodasmetropoles.ufrj.br/textos.htm $>$ Acesso em 08 de agosto de 2006.

Habitação de interesse social: Política ou mercado reflexos sobre a construção do espaço metropolitano. Anais do XIV Encontro Nacional da ANPUR, Rio de Janeiro, Associação nacional de Pós-graduação e pesquisa em Planejamento Urbano e Regional, - 23 -27 de maio de 2011. p.01-20.

. (Org.). O Programa Minha Casa Minha Vida e seus efeitos territoriais. Rio de Janeiro: Letra Capital, 2013.

Especial sobre o pacote habitacional Minha Casa, Minha Vida, FASE. Rio de Janeiro, 2009. Disponível em <http://www.fase.org.br/v2//pagina.php?id=3108>. Acesso em 15 jun. 2015.

CEF - Caixa Econômica Federal. Minha Casa Minha Vida. Cartilha da CAIXA.2009.

DENALDI, Rosana. Política Habitacional, financiamento e a produção da cidade: avanços e impasses. In: ZIMERMAN, Artur e DIETRICH, Ana Maria (Org.). Café com PP: Novas abordagens de políticas públicas no Brasil. 1ed.Santo André: UFABC, 2012, p.37-53. 
Os 10 anos do atual programa de moradia social no Brasil: uma trajetória de (des)caminhos.

Revista Ensaios, vol. 14, jan-jun de 2019.

FUNDAÇÃO JOÃO PINHEIRO. Centro de Estatística e Informações Déficit habitacional no Brasil 2011-2012 / Fundação João Pinheiro. Centro de Estatística e Informações - Belo Horizonte, 2015. 126p.

GONÇALVES, Rafael Soares, Des Expositions aux Jeux Olympiques : Grands événements internationaux et interventions urbaines à Rio de Janeiro dans une perspective historique. Problèmes d'Amérique latine, v.4, 2017, p.37-55.

GONÇALVES, Rafael Soares, FREIRE, Leticia Luna e BAUTÈS, Nicolas, Rio de Janeiro 2016 ou les travers de la ville olympique. Problèmes d'Amérique latine, v. 4, 2017, p. 7-15.

JESUS, Patrícia e DENALDI, Rosana, Experiências de regulação urbana e suas possibilidades: análise a partir do Programa Minha Casa Minha Vida na Região do Grande abc (São Paulo). EURE Revista Latinoamericana de Estudios Urbano Regionales, v. 44, 2018, p.91-111.

MARICATO, Ermínia. A Nova Política Nacional de Habitação. Jornal O valor, São Paulo,24 nov. 2005.

MATOSO, Jorge e MUNIZ, Sueli. Habitação: a habitação no governo Lula, 2006 in https://fpabramo.org.br/2006/08/23/habitacao-a-habitacao-no-governo-lula-1-por-jorgemattoso-e-suely-muniz/ (acesso junho de 2019)

RIBEIRO, Rodrigo Lopes Cavalcanti, Na Periferia do Centro: Intervenções Públicas, Vida Condominial e o Mercado de "Doação" em dois conjuntos habitacionais do Rio de Janeiro, Mestrado em Sociologia, Universidade Federal Fluminense, 2016.

SERAFIM, L. Impactos da participação social no Brasil: a incorporação da pauta da reforma urbana nas políticas do Ministério das Cidades (2003-2010). Anais do 2012 Congress of the Latin American Studies Association, San Francisco, California May 23- 26, 2012.

SILVA, C. A. Os Caminhos e descaminhos da política de habitação em Portugal e no Brasil no contexto de crise econômica do início do século XXI. Tese de doutorado em Serviço Social. Pontifícia Universidade Católica do Rio de Janeiro, Rio de Janeiro. 2015.

Políticas Sociais no Brasil: seus desdobramentos históricos e o debate do terceiro setor. In: V Jornada Internacional de Políticas Públicas. São Luiz, 2011. Anais... São Luiz: JOIMPP, 1989. p.1-11.

Repercussões da Política de Habitação no Brasil. In: XII- Encontro Nacional de pesquisadores em serviço Social. Rio de Janeiro, 2010. Anais... Rio de Janeiro.2010, p. $1-10$.

VALLE, Josiane e GONÇALVES, Rafael Soares, Intervención urbana y megaeventos en Río de Janeiro: resistência de Vila Autódromo a la política de remoción. Limaq. Revista de Arquitectura de la Universidad de Lima, v. 4, 2018, p.123-141. 